\title{
PAX8 promotes tumor cell growth by transcriptionally regulating $E 2 F 1$ and stabilizing RB protein
}

\author{
CG Li ${ }^{1,3}, \mathrm{JE} \mathrm{Nyman}^{1}$, AW Braithwaite ${ }^{1,2}$ and MR Eccles ${ }^{1}$ \\ ${ }^{1}$ Department of Pathology, Dunedin School of Medicine, University of Otago, Dunedin, New Zealand and ${ }^{2}$ Cell Transformation \\ Unit, Children's Medical Research Institute, University of Sydney, Sydney, New South Wales, Australia
}

\begin{abstract}
The retinoblastoma protein (RB)-E2F1 pathway has a central role in regulating the cell cycle. Several PAX proteins (tissue-specific developmental regulators), including PAX8, interact with the RB protein, and thus regulate the cell cycle directly or indirectly. Here, we report that PAX8 expression is frequent in renal cell carcinoma, bladder, ovarian and thyroid cancer cell lines, and that silencing of PAX8 in cancer cell lines leads to a striking reduction in the expression of E2F1 and its target genes, as well as a proteasome-dependent destabilization of RB protein, with the $R B 1 \mathrm{mRNA}$ level remaining unaffected. Cancer cells expressing PAX8 undergo a $G_{1} / S$ arrest and eventually senesce following PAX8 silencing. We demonstrate that PAX8 transcriptionally regulates the $E 2 F 1$ promoter directly, and $E 2 F 1$ transcription is enhanced after $\mathrm{RB}$ depletion. $\mathrm{RB}$ is recruited to the PAX8-binding site, and is involved in PAX8-mediated E2F1 transcription in cancer cells. Therefore, our results suggest that, in cancer, frequent and persistent expression of PAX8 is required for cell growth control through transcriptional activation of $E 2 F 1$ expression and upregulation of the RB-E2F1 pathway.
\end{abstract}

Oncogene (2011) 30, 4824 4834; doi:10.1038/onc.2011.190; published online 23 May 2011

Keywords: cell cycle; E2F1; PAX8; RB; senescence

\section{Introduction}

PAX8 is a cell-lineage-specific transcription factor, best characterized for its role in thyrocyte differentiation through activation of thyroid differentiation markers: thyroglobulin, thyroperoxidase and sodium/iodide symporter (Zannini et al., 1992; Esposito et al., 1998; Fabbro et al., 1998; Ohno et al., 1999). Pax8 homozygous null mutant mice have congenitally smaller thyroids compared with heterozygous mutant or wild-type littermates,

Correspondence: Professor MR Eccles, Department of Pathology, Dunedin School of Medicine, University of Otago, PO Box 913, Great King Street, Dunedin, Otago 9054, New Zealand.

E-mail: michael.eccles@otago.ac.nz

${ }^{3}$ Current address, Department of Pediatrics, Stanford University, Stanford, CA 94305, USA.

Received 10 January 2011; revised 3 April 2011; accepted 5 April 2011; published online 23 May 2011 and suffer from hypothyroidism (Mansouri et al., 1998). Similarly, in humans, heterozygous mutations of PAX8 are associated with congenital thyroid dysgenesis (Macchia et al., 1998; Vilain et al., 2001).

During fetal development, Pax8 is also expressed in three sites in addition to thyroid. Early in central nervous system development, Pax 8 is expressed in the midbrain-hindbrain boundary (Stoykova and Gruss, 1994). Pax 8 is also expressed during inner ear development and in the cells of the pronephric, mesonephroic and metanephric lineages (Plachov et al., 1990; Pfeffer et al., 1998; Bouchard et al., 2002). Although Pax8 knockout mice have normal kidney development (Mansouri et al., 1998), either a heterozygous or a homozygous $\operatorname{Pax} 8$ null mutation together with a background of a Pax2 heterozygous null mutation in mice results in major loss, or complete depletion, respectively, of the nephric cell lineage through increased apoptotic cell death (Bouchard et al., 2002; Narlis et al., 2007). These data suggest an early role for Pax 8 together with Pax 2 in nephron lineage specification and/or survival.

The cell cycle is the fundamental process controlling cell proliferation. Emerging evidence has demonstrated that the cell cycle also critically modulates cellular differentiation. Cellular commitment to terminal differentiation is accompanied by a permanent exit from the cell cycle in the $G_{1}$ phase (Buttitta and Edgar, 2007). The retinoblastoma protein (RB)-E2F1 pathway is central to the regulatory mechanism of cell-cycle control, and deregulation of this pathway is one of the key factors contributing to tumorigenesis. RB is best characterized for its dual tumor-suppressor role; first, by negatively regulating the cell-cycle progression at the $\mathrm{G}_{1} / \mathrm{S}$ transition by modulating the activity of E2F transcription factors (Weinberg, 1995), and second, by binding and modulating tissue-specific transcription factors to promote terminal differentiation (Sellers et al., 1998). Classically, RB binds to and inhibits E2F transactivation activity (Flemington et al., 1993). Upon phosphorylation by cyclin/cyclin-dependent kinase complexes, RB dissociates from E2F, which then becomes transcriptionally active in the late $G_{1}$ phase (Chellappan et al., 1991; Burkhart and Sage, 2008). RB also modulates E2F activity by additionally recruiting chromatin remodeling factors (Frolov and Dyson, 2004). RB activity is regulated through post-translational modifications, including phosphorylation (primarily), acetylation and methylation (Chan et al., 2001; Munro et al., 
2010). Although cellular RB expression is stable during cell cycle and differentiation (Yen et al., 1997), it has been shown to be targeted for proteasome-dependent degradation by cellular and viral oncoproteins: gankyrin, MDM2, human parpaillovirus E7, Epstein-Barr virus nuclear antigen-3C and human megalovirus pp71 protein (Boyer et al., 1996; Berezutskaya and Bagchi, 1997; Higashitsuji et al., 2000; Kalejta and Shenk, 2003; Knight et al., 2005; Sdek et al., 2005), and only A-type lamins have so far been identified to contribute to the stability of RB protein (Nitta et al., 2006).

Unlike RB, E2F1 expression is strictly cell-cycle dependent, and its protein is unstable owing to active degradation through the ubiquitin-proteasome pathway (Hofmann et al., 1996). Physical interaction between E2F1 and hypophosphorylated RB has been shown to be required for its protein stability (Hofmann et al., 1996). Upon release from RB in the late $G_{1}$ phase, E2F1 binds to and activates its own promoter, resulting in accumulation of newly synthesized free E2F1, in order to activate gene expression required for S-phase entry (Johnson et al., 1994). E2F1 expression is subsequently downregulated through suppression of E2F7-E2F8 on the E2F1 promoter (Zalmas et al., 2008). Although downstream target genes of E2F1 are well established, relatively little is known about the upstream regulators of the steady-state expression of E2F1. The Myc oncoprotein is also thought to contribute to pre-S-phase $E 2 F 1$ expression through regulation of the E2F1 promoter (Fernandez et al., 2003; Leung et al., 2008).

PAX8 has emerged as a potential diagnostic marker for ovarian carcinomas (Hibbs et al., 2004; Bowen et al., 2007), renal cell carcinomas (RCCs) (Tong et al., 2009) and pancreatic endocrine tumor (Long et al., 2010). In addition, frequent expression of PAX8 has been reported in Wilms tumor, thyroid carcinoma and glioma. Little is known about the biological significance of PAX8 expression in cancer. Several observations suggest that Pax 8 could directly or indirectly influence cell growth and survival; first, inhibiting Pax8 expression in a rat thyroid cell line caused growth reduction (Rossi et al., 1995), suggesting that Pax8 influences cell proliferation or survival. Second, Pax 8 is one of the tissue-specific factors that complexes with $\mathrm{RB}$ to promote the expression of thyroid differentiation genes in rat thyrocyte cells (Miccadei et al., 2005). Further- more, we have shown previously that PAX8 positively regulates the expression of telomerase RNA $(h T R)$ and telomerase reverse transcriptase ( $h T E R T)$ in colorectal and glioma cell lines (Chen et al., 2008), suggesting that PAX8 expression could be critical for maintenance of telomeres and immortalization.

The observation that PAX8 is required for the growth and differentiation of several cell types suggests that interaction between PAX8 and RB could likewise have an important role in cell growth and differentiation. In spite of significant progress in recent years in understanding the regulation of the cell cycle, it remains unclear as to how the growth and differentiation of a tissue are coordinated together with the regulation of the cell cycle in a tissuespecific manner so as to facilitate terminal differentiation, and in particular how this process is disrupted in cancer. To determine whether PAX8 is a tissue-specific regulator of cell proliferation and differentiation that becomes dysregulated in cancer, we silenced $P A X 8$ expression in multiple cancer cell lines using small interfering RNAs (siRNA). Silencing of PAX8 causes a reduction in E2F1 mRNA and protein levels in cancer cell lines, as well as a reduction in the levels of $\mathrm{E} 2 \mathrm{~F} 1$ target genes, including cyclin-A2 (CCNA2) and CDC6, induction of $\mathrm{G}_{1} / \mathrm{S}$ cellcycle arrest and onset of cellular senescence. We further show that PAX8 binds to and transactivates the E2F1 promoter, and that PAX8 is also required for RB stabilization, thereby forming a negative feedback loop, which represses PAX8-mediated transactivation of the E2F1 promoter. Our results therefore support the hypothesis that PAX8 is important for cancer cell growth and viability through regulation of key proteins involved in cell-cycle control.

\section{Results}

PAX8 expression in human cancer cell lines

As indicated above, it has been reported that PAX8 is expressed in subsets of normal adult renal tissue and persistently expressed in dedifferentiated cells characterizing RCCs (Tong et al., 2009). To confirm this observation, we performed immunohistochemical analysis of PAX8 expression on $10 \mathrm{RCC}$ tumors and their normal kidney counterparts. An example is shown in Figure 1, which shows that PAX8 exhibits widespread

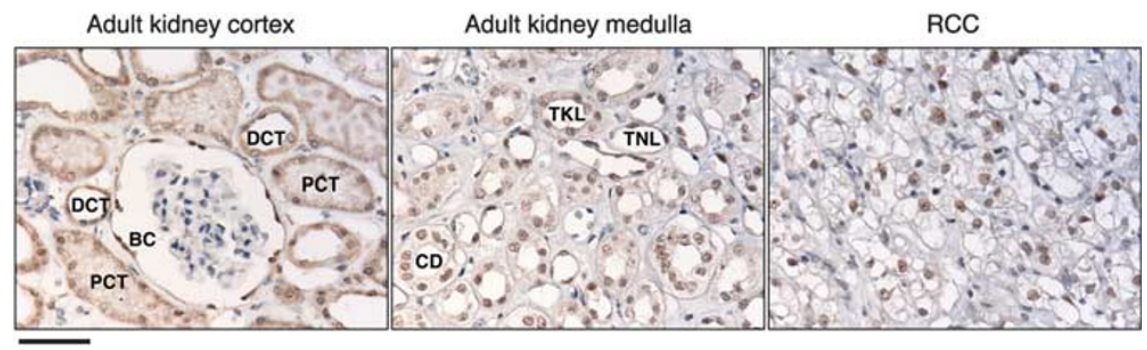

Figure 1 PAX8 is expressed in RCC and adult normal kidney tissues. PAX8 expression was analyzed in 10 RCC sections and their normal kidney counterparts (cortex and medulla). Staining was consistently observed in the RCC cells, as well as in the cortex and medulla of adult kidney. A representative set is presented here. Abbreviations: PCT, proximal convoluted tubule; DCT, distal convoluted tubule; BC, Bowman's capsule; CD, collecting duct; RCC, renal cell carcinoma; TNL, thin loop of Henle; TKL, thick loop of Henle. Magnification: $\times 40$. The scale bar represents $50 \mu \mathrm{m}$. 

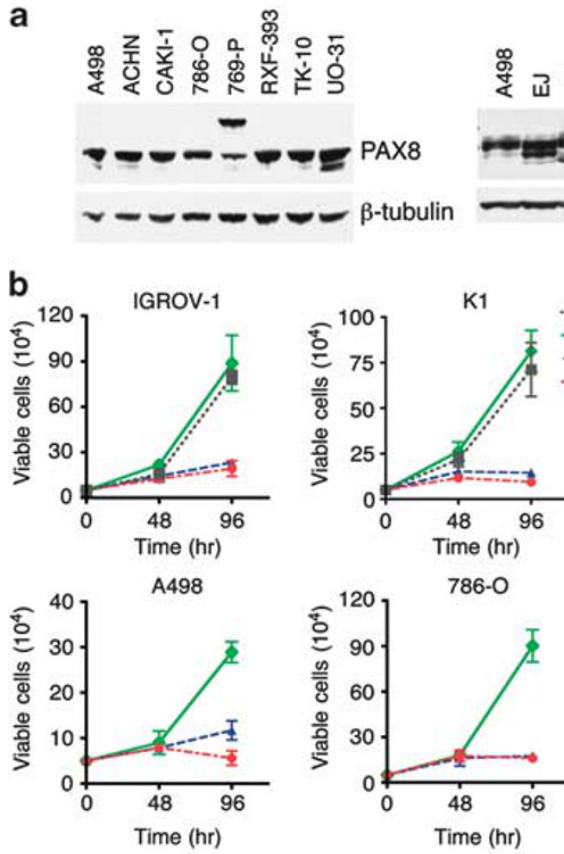$$
\text { 흠 }
$$

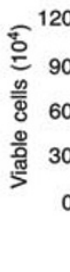

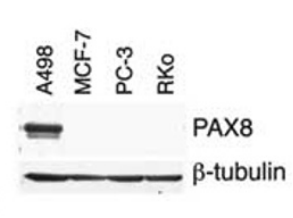

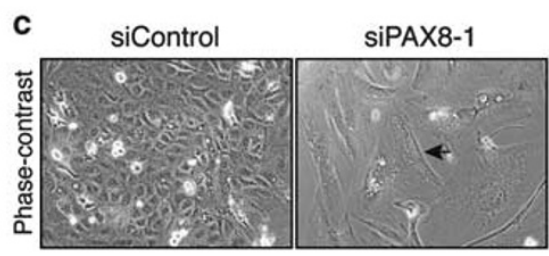

d

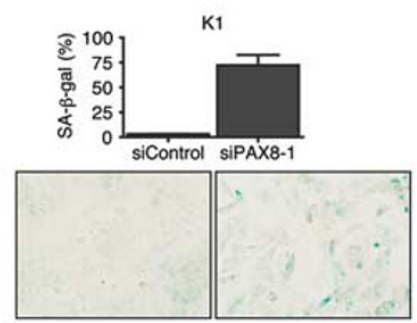

Figure 2 PAX8 is frequently expressed in cancer cell lines and is required for cancer cell growth. (a) Whole-cell lysates of 19 cancer cell lines were subjected to immunoblotting using the indicated antibodies. (b) Cell viability assessment. The effect of PAX8 knockdown on the viability of A498, 786-O, IGROV-1 and K1 cells was determined using trypan blue exclusion assay. (c, d) K1 cells were transfected with the indicated siRNA. At $120 \mathrm{~h}$ post transfection, cells were examined by (c) phase-contrast microscopy and (d) stained for SA- $\beta$-gal activity. Total cell number and stained cell number were counted in a blind manner. The data are the means \pm s.e.m. of two independent experiments. SA- $\beta$-gal, senescence-associated $\beta$-galactosidase; siRNA, small interfering RNA.

expression in RCC, as well as in specific regions of the normal kidney, with strongest staining evident in the thin loop of Henle, the distal convoluted tubules and the collecting ducts, and weakest staining in the proximal convoluted tubule. Next we assessed the generality of PAX8 expression in cancer by determining PAX8 protein levels by immunoblotting (Figure 2a). High levels of PAX8 were detected in RCCs, bladder carcinomas, ovarian carcinomas and thyroid cancers. Furthermore, PAX8 was also detected in two retinoblastoma cell lines (Y79 and WERI-Rb), but undetectable in J82 bladder, MCF-7 breast, PC-3 prostate and RKO colon cancer cell lines. Immunoblotting detected multiple PAX8 bands in most cell lines. The multiple bands were likely isoforms related to PAX8 (Poleev et al., 1995), because PAX8 as well as the multiple bands were silenced (Supplementary Figure S1A) when PAX8 was silenced using two $P A X 8$ targeting siRNAs (siPAX8-1 and siPAX8-2).

\section{$P A X 8$ silencing in cancer cells leads to growth retardation and triggers senescence}

To investigate whether PAX8 expression in the above cancer cell lines confers a growth advantage, we initially examined the effect of PAX8 knockdown on cell viability using two RCC (A498 and 786-O), one ovarian (IGROV-1) and one thyroid (K1) cancer cell line, using the trypan blue exclusion assay. Cancer cell lines transfected with PAX8 siRNAs showed severe growth retardation following transfection, as compared with
siControl-transfected cells (Figure 2b) or untransfected cells (IGROV-1 and K1). In addition, we observed morphological changes of PAX8-deficient cells using phase-contrast microscopy. PAX8-depleted cells exhibited an enlarged and flattened morphology, demonstrating the typical phenotype of senescent cells (Figure 2c). To confirm that senescence was induced following PAX8 silencing, we performed histochemical detection of senescence-associated (SA) $\beta$-galactosidase (SA- $\beta$ gal) activity, a widely used marker of senescence. Less than $3.1 \%$ of the control cells were SA- $\beta$-gal positive, but a marked increase of SA- $\beta$-gal-positive cells (70.3\%) was observed in $\mathrm{K} 1$ thyroid cancer cells following PAX8 siRNA transfection (Figure 2d). Similar results were also observed in three additional cancer cell lines (Supplementary Figure S1B), suggesting that the loss of PAX8 expression induces senescence of cancer cells.

Silencing of PAX8 in cancer cells induces cell-cycle arrest To determine whether silencing of PAX8 leads to blockade of cell-cycle progression, flow cytometry was used to study cell-cycle profiles using two RCC cell lines, A498 and 786-O. At $72 \mathrm{~h}$ post siRNA transfection, cells were pulse-labeled with 5-bromodeoxyuridine (BrdU) before flow cytometry. PAX8 silencing led to a significant increase in the number of cells in the $G_{1}$ phase, together with a reduction of the number of cells in the S-phase (Figure 3a). To further examine the effect of PAX8 silencing on the cell cycle, $48 \mathrm{~h}$ after transfection with PAX8 siRNA, when PAX8 was clearly 
a
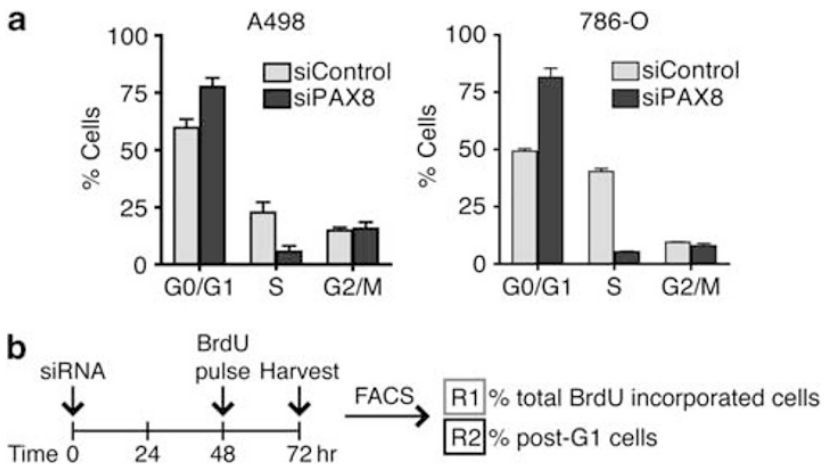

C

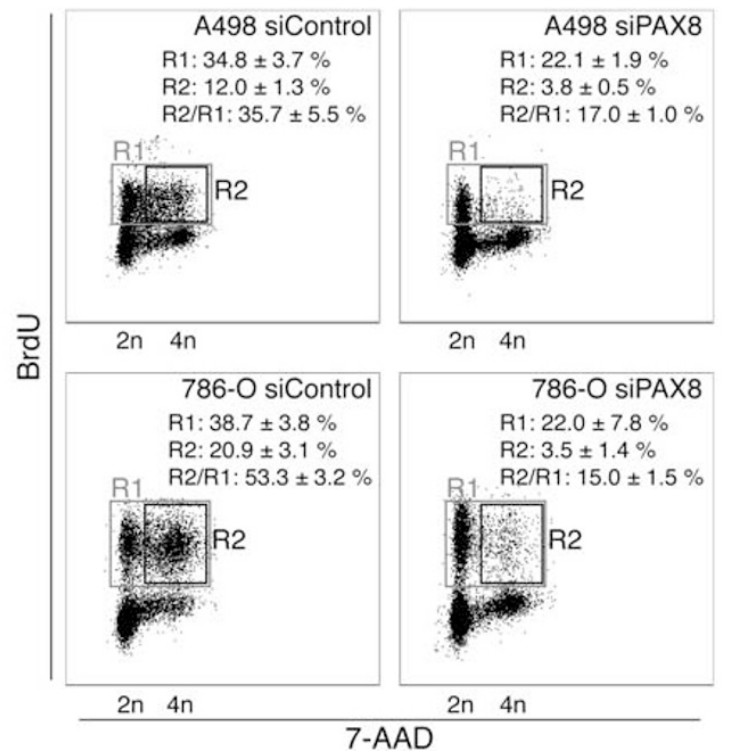

Figure 3 Depletion of PAX8 induces cell-cycle arrest through inhibition of DNA synthesis. (a) A498 and 786-O cells were transfected with the indicated siRNA. The cells were subjected to BrdU incorporation assays at $48 \mathrm{~h}$ post transfection (as described under Materials and methods). The percentage of cells in each cellcycle phase is shown. (b) Experimental design for measuring S-phase progression using BrdU pulse-chase labeling assay. siRNA-transfected A498 and 786-O cells were pulse-labeled for 15 min with $\mathrm{BrdU}$ at $48 \mathrm{~h}$ post transfection. The S-phase cell population was monitored $24 \mathrm{~h}$ after pulse labeling. (c) FACS profiles for the indicated samples. Percentages of total cells with BrdU incorporated (R1, gray) and cells in S-phase (R2, black) were estimated. The data are the means \pm s.e.m. of three independent experiments. BrdU, 5-bromodeoxyuridine; siRNA, small interfering RNA.

depleted (Supplementary Figure S1A), cells were pulsed for $15 \mathrm{~min}$ with BrdU, and then incubated for a further $24 \mathrm{~h}$ after which they were harvested and analyzed using flow cytometry (Figure 3b). Using this technique, we predicted that we would be able to identify phases of the cell cycle that were defective following PAX8 knockdown. Consistent with the cell-cycle profiles, depletion of PAX8 in the cancer cell lines resulted in a strikingly decreased cell population entering the S-phase. For example, in 786-O cells, upon PAX8 silencing, only $15.0 \pm 1.5 \%$ of the cells that had incorporated BrdU progressed to S-phase, compared with the control $(53.3 \pm 3.2 \%$; R2/R1; Figure 3c). Similar results were observed with A498 cells (Figure 3c) and several other cell lines derived from other cancer types (Supplementary Table S1). Thus, PAX8 silencing leads to an arrest of cell-cycle progression at the $G_{1} / S$ phase border. Collectively, these data suggest that PAX8 expression could confer a growth advantage to cancer cells.

\section{$P A X 8$ binds to and is required for transactivating $\mathrm{E} 2 \mathrm{~F} 1$ promoter activity}

A preliminary microarray analysis was performed to profile gene expression changes following PAX8 silencing in A498 cells. To minimize off-target siRNA effects, only genes with a greater than twofold change in expression in common between two different siRNA treatments using either siPAX8-1 or siPAX8-2 were further analyzed. The array data were evaluated using Gene Onotology and Ingenuity Pathway Analysis. The analysis revealed downregulation of several cell-cycle regulators following PAX8 silencing (data not shown). Interestingly, E2F1, a key regulator of S-phase entry, and many of its transcriptional targets were found to be downregulated in PAX8 siRNA-transfected cells. We then selected E2F1, CCNA2, CDC6, MCM3 and DHFR for further validation using quantitative real time PCR (qPCR) analysis. Consistent with preliminary microarray data, validation using qPCR demonstrated a substantial downregulation of these E2F1 targets following PAX8 knockdown (Figure 4a). In addition, we observed the same altered gene expression pattern in the 786-O cells (Figure 4a). Next, we confirmed the expression changes at the protein level using A498, 786-O, IGROV-1 and K1 cell lines, by immunoblotting using the indicated antibodies. Corresponding to the qPCR data, both E2F1 and cyclin-A proteins were markedly reduced in siPAX8-transfected cells (Figure 4b). Similarly, CDC6 protein level was also reduced (Figure $4 \mathrm{~b}$ ). The data obtained from both qPCR and immunoblotting show that PAX8 knockdown leads to downregulation of several E2F1 target genes.

As E2F1 gene expression, demonstrated above, was nearly abolished upon PAX8 knockdown, we reasoned that the E2F1 promoter activity could be sensitive to PAX8 dosage. To investigate this possibility, we silenced PAX8 expression transiently in K1 cells using siRNAs. At $24 \mathrm{~h}$ post siRNA transfection, we transfected a luciferase reporter driven by the E2F1 promoter. The luciferase assays showed that the exogenous E2F1 promoter activity was reduced threefold upon PAX8 knockdown (Figure 4c). This indicates a requirement for PAX8 in regulating basal E2F1 gene expression. Next, to determine whether PAX8 directly transactivates the $E 2 F 1$ promoter we investigated the $E 2 F 1$ promoter for regulation by PAX8 protein through direct binding to the endogenous promoter. PAX8 putative binding sites were identified using a web-based promoter analysis tool, ConTra (Hooghe et al., 2008; Figure 4d). To determine whether PAX8 is recruited to these sites, chromatin immunoprecipitation (ChIP) assays were performed using an anti-PAX8 antibody, followed by qPCR analysis using site-specific primers. A region 


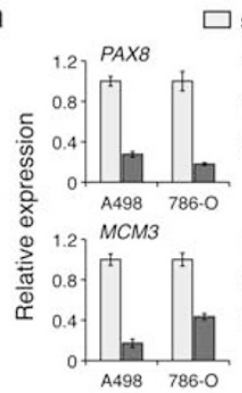

C
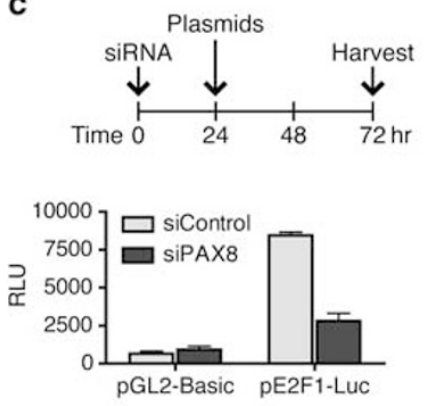

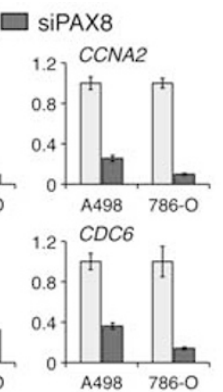

b

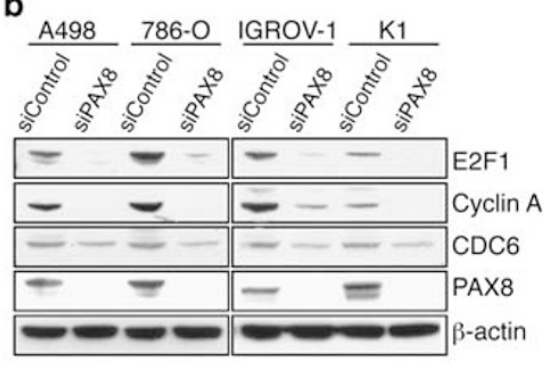

d

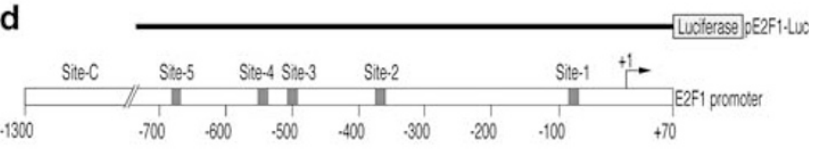

ChIP: PAX8

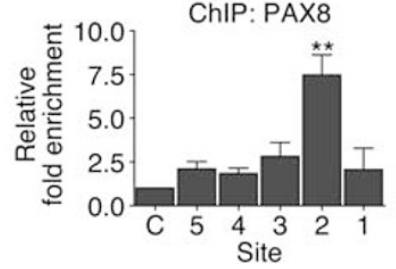

Figure 4 PAX8 directly regulates E2F1 expression through stimulation of E2F1 promoter activity. The effects of PAX8 knockdown on the expression of E2F1 targets, including E2F1 itself, were analyzed at (a) the transcript and (b) the protein level. (a) Total RNA was isolated from the indicated sample at $48 \mathrm{~h}$ post transfection and subjected to qPCR analysis. Gene expression levels were normalized to the expression of the housekeeping genes, PPIB and YWHAZ, and presented relative to the siControl-transfected samples. The data are means \pm s.d. of three independent experiments. (b) Whole-cell lysates were extracted from siRNA-transfected A498, 786-O, IGROV-1 and K1 cells at $96 \mathrm{~h}$ post transfection. The lysates were subjected to immunoblotting using the indicated antibodies. (c) Effect of PAX8 knockdown on E2F1 promoter activity was assessed using luciferase assay. At $24 \mathrm{~h}$ post siRNA transfection, K1 cells were co-transfected with the indicated luciferase-promoter plasmid and pCMV- $\beta$-gal plasmid. Relative luciferase units (RLUs) are normalized to $\beta$-gal activity. (d) The promoter sequence of pE2F1-Luc was analyzed using the ConTra web tool. Sitespecific primers were designed and used for ChIP-qPCR amplification for each putative PAX8-binding site (Sites-1 to -5). A region without any putative PAX8-binding site (Site-C) was used as the negative control. A498 cells were subjected to ChIP using a PAX8 antibody. IP chromatin was analyzed by ChIP-qPCR using site-specific primers. Fold enrichment is shown relative to Site-C (=1.0). Statistical significance was assessed using one-way analysis of variance; $* * P<0.01$. The data shown in panels $\mathbf{c}$ and $\mathbf{d}$ are the means \pm s.e.m. of three and two independent experiments, respectively. ChIP, chromatin immunoprecipitation; IP, immunoprecipitation; qPCR, quantitative PCR; siRNA, small interfering RNA.

without a putative PAX8-binding site (Site-C) was selected as the calibrator to calculate relative fold enrichment. The ChIP-qPCR results revealed a significant relative fold enrichment of PAX8 binding to the Site-2 region $(7.5$-fold, $P<0.01)$ relative to the control site (Site-C), which has no putative PAX8-binding site (Figure 4d). Interestingly, this region containing Site-2 has also been shown to be enriched in Myc-immunoprecipitated chromatin (Leung et al., 2008). Collectively, these data support the hypothesis that E2F1 is a novel PAX8 target gene.

\section{$P A X 8$ and $R B$ function together in mediating E2F1 transcription}

As seen above, PAX8 is required for E2F1 gene expression. It is well documented that $E 2 F 1$ transcriptional activity is tightly regulated by RB through the formation of a complex of RB and E2F1 proteins. Furthermore, RB has been demonstrated to function as a PAX8 transcriptional co-activator in regulating gene expression in the thyroid (Miccadei et al., 2005). Therefore, it is possible that RB is involved in the PAX8-mediated regulation of E2F1 expression. To investigate this possibility, we initially studied the $R B$ transcript level following PAX8 knockdown using A498 and 786-O cells. qPCR analysis revealed no substantial changes in $R B$ mRNA levels following PAX8 silencing (Figure 5a). Next, we examined RB protein level in the PAX8-depleted cells using multiple cancer cell lines. Surprisingly, the RB protein level was markedly depleted with the loss of PAX8 (Figure 5b), suggesting that the RB protein was destabilized in the absence of PAX8. The destablization effect was also observed when RB was constitutively expressed (pCMV$\mathrm{RB}$; compare the first, the second and the third lanes; Figure 5c). Further experiments with the proteasome inhibitor (MG132) indicated that RB depletion in PAX8 knockdown cells was dependent on proteasomal degradation. Treatment of PAX8-depleted cells (K1) with MG132 caused an accumulation of RB (compare the second and the fourth lane; Figure 5c). Furthermore, the requirement of PAX8 for RB stability was also confirmed when exogenous $\mathrm{RB}$ expression was shown to behave in a manner similar to that of endogenous RB (compare the third and fifth lanes; Figure 5c).

Co-occupancy of PAX8 and RB on a thyroid-specific gene promoter has been demonstrated collectively using 


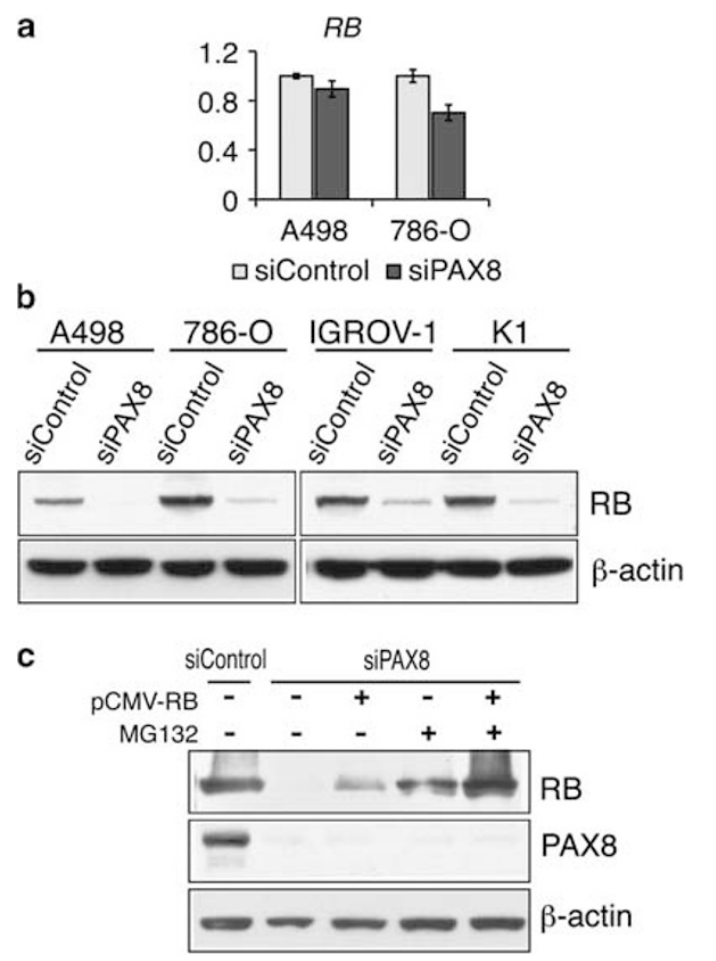

Figure 5 PAX8 is required for RB protein stability. The effect of PAX8 knockdown on RB expression at (a) the transcript and (b) the protein levels. (a) Total RNA was isolated from the indicated sample at $48 \mathrm{~h}$ post-transfection, and subjected to qPCR analysis. Gene expression levels were normalized to the expression of the housekeeping genes, $P P I B$ and $Y W H A Z$, and presented relative to the siControl-transfected samples. The data are means \pm s.d. of three independent experiments. (b) Whole-cell lysates were extracted from siRNA-transfected A498, 786-O, IGROV-1 and $\mathrm{K} 1$ cells at $96 \mathrm{~h}$ post transfection. The lysates were subjected to immunoblotting using the indicated antibodies. (c) Effects of proteasome inhibition on RB depletion in response to PAX8 knockdown. K1 cells were transfected with the indicated siRNA. After $24 \mathrm{~h}$, cells were transfected either with a vector control (-) or with pCMV-RB $(+)$. At $48 \mathrm{~h}$ post DNA transfection, the cells were incubated in medium with or without MG132 for $12 \mathrm{~h}$. Whole-cell lysates were then extracted and subjected to immunoblotting using the indicated antibodies. qPCR, quantitative PCR; RB, retinoblastoma; siRNA, small interfering RNA.

luciferase promoter-reporter assays, ChIP analyses and co-IP in rat thyroid cells (Miccadei et al., 2005). On the basis of these previous findings, we speculated that RB could also function as a cofactor in PAX8-mediated $E 2 F 1$ transcription. Therefore, we sequentially transfected siRNAs targeting $R B$, followed $24 \mathrm{~h}$ later by cotransfection with a Pax8 expression construct and the E2F1 promoter luciferase reporter into $\mathrm{K} 1$ thyroid cancer cells. Validation of the knockdown and overexpression is shown in Supplementary Figure S2. The luciferase assays revealed that transactivation of the E2F1 promoter by Pax8 (2.4-fold) was enhanced in the absence of RB (4.1-fold; Figure 6a). Collectively, these data demonstrate that $\mathrm{RB}$ represses Pax8-mediated E2F1 transcription in thyroid cancer cells.

To determine whether coregulation of the E2F1 promoter by PAX8/RB also occurs in RCC cell lines, we first performed coimmunoprecipitation (Co-IP) to a

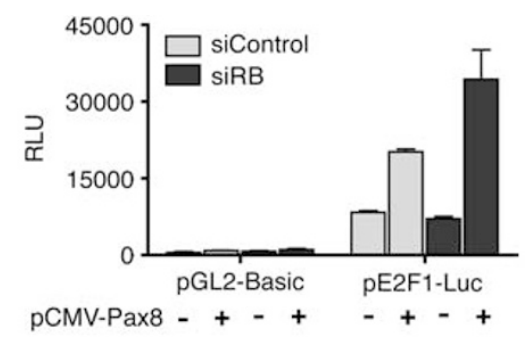

b
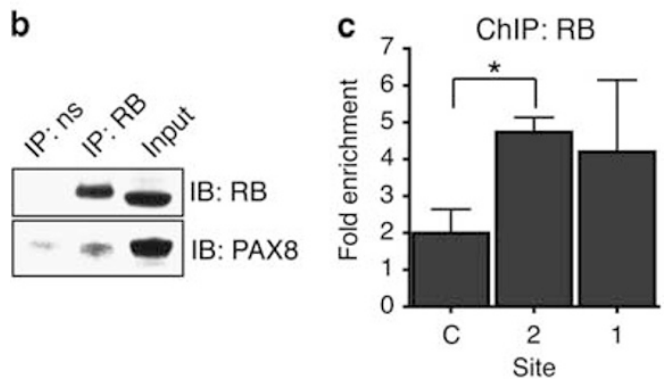

Figure 6 PAX8 and RB co-occupy the E2F1 promoter and function antagonistically in regulating E2F1 promoter activity. (a) The effect of RB knockdown on the PAX8 transactivation of E2F1 promoter activity. At $24 \mathrm{~h}$ post-siRNA transfection, K1 cells were co-transfected with either vector control or pCMV-Pax8, as well as the indicated luciferase-promoter plasmid and the pCMV- $\beta$ gal plasmid. The relative luciferase units (RLUs) are normalized to $\beta$-gal activity. (b) A498 whole-cell lysate was subjected to IP using an RB antibody. IP protein complexes were analyzed using immunoblotting (IB) to detect $\mathrm{RB}$ and PAX8 proteins. NS indicates IP using a nonspecific antibody. (c) A498 cells were subjected to ChIP using a PAX8 antibody. IP chromatin was analyzed by ChIP-qPCR, using primers targeting the putative PAX8-binding site (Site-2). In addition, Site-1, which contains the characterized RB-E2F1-binding site, was used as a positive control. The negative control Site-C was used for comparison. Fold enrichment is shown relative to the negative control site (Site-C). Statistical significance was assessed using unpaired Student's $t$-test; ${ }^{*} P<0.05$. Data for $\mathbf{a}$ and $\mathbf{c}$ are the means \pm s.e.m. of three independent experiments for each panel. ChIP, chromatin immunoprecipitation; IP, immunoprecipitation; qPCR, quantitative PCR; RB, retinoblastoma; siRNA, small interfering RNA.

demonstrate an in vivo interaction between endogenous PAX8 and RB in A498 RCC cells. Endogenous RB was immunoprecipitated followed by immunoblotting with PAX8 antibody (Figure 6b), confirming the formation of the PAX8-RB complex in RCC cells. Next, we asked whether regulation of the $E 2 F 1$ promoter by $\mathrm{PAX} 8 / \mathrm{RB}$ is due to co-occupancy of RB on the same PAX8binding site (Site-2). We performed ChIP assays using an antibody against RB and used primers specific for the Site-1 region as the positive control. This region contains the E2F1-binding site (Johnson et al., 1994), which was shown to be enriched in RB-immunoprecipitated chromatin (Wells et al., 2003). The results showed that the PAX8-binding site (Site-2) was significantly enriched in the RB-immunoprecipitated chromatin as compared with that in the negative control Site-C $(P<0.05)$. Similarly, the positive control, Site-1, was also enriched, as expected (Site-2, 4.7-fold; Site-1, 4.2-fold; Site-C 2.0-fold; Figure 6c). These findings suggest that $\mathrm{RB}$ is recruited to the PAX8-binding site and is involved in PAX8-mediated E2F1 transcription in RCC cells. Together, our results demonstrate that PAX8 
is required for RB stabilization, and together with $\mathrm{RB}$, regulates $E 2 F 1$ expression in the cell-cycle controlregulatory pathway.

\section{Discussion}

Here we describe a new role for PAX8 expression in human tumor cell lines, with implications for understanding the mechanisms of tumor-associated growth regulation. We show that the developmental transcription factor, PAX8, which is frequently expressed in human tumors, is capable of promoting tumor cell growth through direct regulation of the $E 2 F 1$ promoter and upregulation of E2F1 expression. Regulation of both E2F1 levels and RB stability by PAX8 in tumor cells might be a reflection of mechanisms controlling cell-cycle progression and exit upon terminal differentiation in normal cells, except that in tumor cells there is a failure of the normal processes to turn $P A X 8$ expression off, which may be important to understand why the tumor cells never terminally differentiate. However, it is paradoxical that PAX8 also promotes RB protein stability, as it seems that PAX8 simultaneously regulates a function that opposes the facilitation of E2F1 expression in tumor cell lines, as $\mathrm{RB}$ is known to inhibit the role of E2F1 (Dyson, 1998). We propose a model below to potentially explain the function of PAX8 in tumor cells, which may help to resolve the paradox.

Briefly, the key points of our model (Figure 7) are as follows: in cells that normally express $P A X 8$, PAX8 drives basal levels of $E 2 F 1$. Meanwhile, hypophosphorylated RB binds to E2F1 and prevents transcriptional activation of cell-cycle regulatory genes. We propose that this $\mathrm{PAX} 8$-mediated $E 2 F 1$ regulation could be essential for maintaining the cell's potential to respond to cell proliferation signals before $\mathrm{S}$-phase entry. The tightly restricted basal E2F1 protein level hence serves as 'standby' E2F1 to form a complex with RB. However, PAX8 also interacts with $\mathrm{RB}$ and it stabilizes RB protein levels, which then form a negative feedback loop to modulate PAX8-mediated E2FI

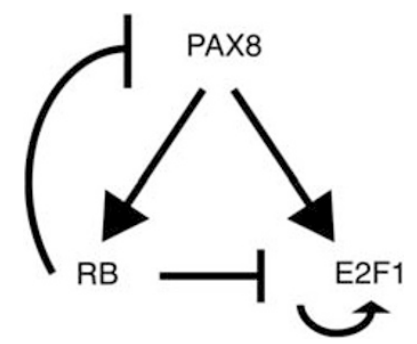

Figure 7 A model of the effect of PAX8 regulation on $\mathrm{RB}$ and E2F1 expression. PAX8 positively regulates both $\mathrm{RB}$ and E2F1 expression through different mechanisms. PAX8 binds to the E2F1 promoter, thereby transcriptionally activating $E 2 F 1$ expression. In comparison, interaction of PAX8 with RB stabilizes the RB protein, which then forms a negative feedback loop, restricting PAX8-mediated E2F1 expression. We propose that this PAX8mediated E2F1 regulation could be essential to maintain cell proliferation signal before S-phase entry. RB, retinoblastoma. expression. Upon $\mathrm{G}_{1} / \mathrm{S}$ transition, $\mathrm{RB}$ is phosphorylated in order to release free E2F1 (Chellappan et al., 1991; Burkhart and Sage, 2008). E2F1 then autoregulates its own promoter to maximize the cellular E2F1 level, which thereby activates the gene expression required for S-phase entry (Johnson et al., 1994). In tumor cell lines with persistently high levels of PAX8 expression, the PAX8-RB complex is also able to bind to and transactivate the E2F1 promoter. However, where the $\mathrm{RB}$ protein has been targeted for proteasomal degradation, or where the $R B$ gene is silenced or mutated, both $\mathrm{E} 2 \mathrm{~F} 1$ and $\mathrm{PAX} 8$ are released from $\mathrm{RB}$, and transactivation of the E2F1 promoter by $\mathrm{PAX} 8$ alone is stronger than transactivation by the PAX8-RB complex, which provides an additional competitive advantage to tumor cells in which RB loss has occurred. If PAX8 is silenced, the $E 2 F 1$ promoter is deactivated. The basal 'standby' levels of E2F1 disappear, RB is no longer required to control E2F1 expression and therefore it is targeted for proteasomal degradation. The acute loss of both E2F1 and RB through PAX8 silencing creates cellular stress that eventually induces senescence.

Members of the $P A X$ gene family encode important regulators of embryogenesis (Dahl et al., 1997). PAX2 and $P A X 8$, however, have overlapping functions and exhibit redundancy in kidney development (Bouchard et al., 2002). Knockout mutations of both Pax2 and Pax8 together are necessary and sufficient to entirely eliminate the nephric lineage (Bouchard et al., 2002). Whereas PAX2 expression diminishes in adult kidneys (Daniel et al., 2001), PAX8 expression persists (Tong et al., 2009). The role of PAX8 expression in adult kidney has not yet been explored, but our immunohistochemical localization of PAX8 expression in adult kidney to regions of putative renal stem cell niches (reviewed in Little and Bertram (2009)) suggests that the role of PAX8 in renal stem cells should be investigated further. $P A X 2$ and $P A X 8$ are both frequently expressed in kidney tumors, including Wilms tumors, and in renal cell carcinomas (Eccles et al., 1995; Daniel et al., 2001; Tong et al., 2006, 2009). The silencing of PAX2 in kidney tumor cell lines has been previously reported to decrease tumor cell growth and survival (Hueber et al., 2006). In comparison, PAX8 has been suggested to be required for the maintenance of $h T E R T$ and $h T R$ expression in low-grade gliomas (Chen et al., 2008).

Human cancers frequently acquire alterations in the RB-E2F1 network (Burkhart and Sage, 2008). However, recent studies show that loss of RB function can lead to centromere dysfunction, chromosome instability (Manning et al., 2010) and inappropriate DNA synthesis in oncoprotein-expressing cells, which would otherwise become senescent through oncogene overexpression (Peeper et al., 2001; Sage et al., 2003). During tumor progression, and before the loss of RB function in tumor cells, PAX8-mediated stabilization of RB protein and simultaneous maintenance of E2F1 expression could maintain responsiveness to proliferation signals in cancer cells at the early stages of tumor development, particularly if RB loss leads to centromere dysfunction and chromosome instability, as these malfunctions may 
cause cells to be particularly vulnerable to senescence. At later stages upon RB loss, increased levels of E2F1 generated by persistent PAX8 expression may contribute to a senescence by-pass mechanism operating during tumorigenesis. Much later, if/when loss of RB has occurred and multiple oncogenic pathways have been activated, the continued expression of PAX8 may then no longer be required, and a gradual loss of PAX8 expression might then be expected. Although a gain of function has been implicated for PAX8 expression in cancer, intriguingly, a gradual loss of PAX8 expression indeed does seem to correlate with the malignant growth of higher-grade tumors, especially in thyroid and pancreatic tumors (Zhang et al., 2006; Long et al., 2010). The oncoprotein, Myc, has also been demonstrated to have a role in maintaining the pre-S-phase E2F1 level (Leung et al., 2008), and interestingly, the proposed Myc-binding site is immediately adjacent to the PAX8-binding site identified in this study (Leung et al., 2008), suggesting that there could be potential for complex formation between PAX8 and Myc in regulating E2F1 transcription. Although Myc expression was shown to be cell-cycle dependent (peaks in the $\mathrm{G}_{1}$ phase; Kelly et al., 1983), PAX8 expression seems to be cell-cycle independent (data not shown). However, this is perhaps not surprising, as PAX8 is responsible for regulating the gene expression required for other cellular processes such as differentiation.

Our results have largely been derived from cancer cell lines. However, the generality of the effect that PAX8 silencing has on senescence, cell-cycle control and E2F1 transcription in multiple cancer types suggests that this is a common non-redundant function of PAX8 expression in cancer. In contrast, PAX2 silencing does not produce a similar effect as the silencing of PAX8, even though PAX2 and PAX8 are often co-expressed in cancer cells. Whether the roles that we have described for PAX8 in cancer cells also apply to developing cells is presently unclear, although several studies have shown that RB is vital for the maintenance of cellular homeostasis through coordination of proliferation and differentiation in normal cells (Skapek et al., 2006). Additional investigations are presently under way to characterize the interactions between PAX2 and PAX8 in cancer and normal cells.

\section{Materials and methods}

\section{Cell culture}

ACHN, CAKI-1, 786-O, 769-P, RXF-393, TK-10, UO-31, J82, Y79, WERI-Rb, IGROV-1 and SKOV-3 cells were grown in RPMI medium (Invitrogen, Carlsbad, CA, USA). A498, EJ, T24, K1 (a gift from D Wynford-Thomas) (Wyllie et al., 1999), MCF-7, PC-3 and RKO cells were cultured in Dulbecco's modified Eagle's medium (Invitrogen). Both media were supplemented with $10 \%$ fetal bovine serum (BioInternational, Auckland, New Zealand). All cells were incubated at $37^{\circ} \mathrm{C}$ under $5 \% \mathrm{CO}_{2}$ in a humidified incubator.

siRNA, plasmids and antibodies

Two siRNAs targeting PAX8 were used: the SMARTpool ON-TARGETplus siPAX8 (siPAX8-1, L-003778-00; Dharmacon,
Lafayette, CO, USA) and the Silencer Pre-designed siPAX8 (siPAX8-2, 114354; Ambion, Austin, TX, USA). SiRNAtargeting RB, the SMARTpool ON-TARGETplus siRB (L-003296-00) and the SMARTpool ON-TARGETplus siControl non-targeting pool (D-001810-10) were purchased from Dharmacon. The expression plasmids used were pCMVRB (a gift from S Hsu and E Harlow; Hsu et al., 2001) and pCMV-Pax8 (a gift from R Di Lauro). pCR3.1 (Invitrogen) was used as a 'filler' to maintain equal total amounts of plasmid DNA transfected. The promoter-luciferase reporter constructs used were $\mathrm{pE} 2 \mathrm{~F} 1-\mathrm{Luc}$, containing an E2F1-flanking sequence from $-728 /+70$ (a gift from K Ohtani) (Johnson et al., 1994), and pGL2-basic (Promega, Madison, WI, USA). pCMV- $\beta$-gal was a gift from P Daniel. The antibodies used in immunohistochemistry, immunoblotting and IP were PAX8 (PA 0300; Biopat, Milan, Italy), $\beta$-tubulin (E7; developed by M Klymkowsky, Developmental Studies Hybridoma Bank), E2F1 (sc-193; Santa Cruz Biotechnology, Santa Cruz, CA, USA), cyclin-A (611268; BD Pharmingen, San Jose, CA, USA), CDC6 (sc-9964; Santa Cruz Biotechnology), $\beta$-actin (ab6276; Abcam, Cambridge, MA, USA), RB (for immunoblotting-554136, BD Pharmingen; for IP-sc-50, Santa Cruz Biotechnology) and CD40 (sc-975; Santa Cruz Biotechnology).

\section{SiRNA and DNA transfection}

Cells were plated (to obtain $30 \%$ confluence the following day) and reverse-transfected with $10 \mathrm{~nm}$ siRNA using Lipofectamine RNAiMAX (Invitrogen) according to the manufacturer's instructions. After transfection, the cells were harvested and processed as described in the figure legends. For siRNA and plasmid co-transfection, cells were first transfected with siRNA as described above. Twenty-four hours after siRNA transfection, the cells were transfected with the indicated plasmid construct using FuGENE-6 (Roche, Indianapolis, IN, USA) according to the manufacturer's instructions. The amount of plasmid constructs transfected is described for each experiment as follows.

\section{Analysis of cell growth and senescence}

For growth analysis, the number of viable cells was determined using the trypan blue exclusion assay at 48 and $96 \mathrm{~h}$ post siRNA transfection. For senescence analysis, cells were siRNA-transfected as described above and photographed at $120 \mathrm{~h}$ post transfection using a phase-contrast microscope. For SA- $\beta$-gal staining, at $120 \mathrm{~h}$ post siRNA transfection, cells were fixed for $5 \mathrm{~min}$ (room temperature) in $4 \%$ paraformaldehyde, washed and incubated at $37^{\circ} \mathrm{C}$ with 5-bromo-4-chloro-3indolyl $\beta$-D-galactopyranoside $(1 \mathrm{mg} / \mathrm{ml})$ and dissolved in a solution containing $40 \mathrm{~mm}$ citric acid $(\mathrm{pH} 6.0), 5 \mathrm{~mm}$ potassium ferrocyanide, $5 \mathrm{~mm}$ potassium ferricyanide, $150 \mathrm{~mm} \mathrm{NaCl}$ and $2 \mathrm{mM} \mathrm{MgCl}_{2}$. After $24 \mathrm{~h}$ of incubation, stained cultures were viewed under bright-field illumination and photographs were taken at $\times 10$ magnification. The percentage of SA- $\beta$-galpositive cells was determined by counting in a blind manner.

\section{Flow cytometry}

For quantitation of cells in the $G_{0} / G_{1}, S$ and $G_{2} / M$ phases of cell cycle, siRNA-transfected cells (described above) were incubated with $\operatorname{BrdU}(5 \mu \mathrm{M})$ at $72 \mathrm{~h}$ post siRNA transfection for $15 \mathrm{~min}$ and harvested. The cells were processed using the BrdU Flow Kit (BD Pharmingen). For quantitation of cells progressing through the cell cycle, siRNA-transfected cells were incubated with BrdU as described above at $48 \mathrm{~h}$ post transfection, washed and incubated in culture medium for another $24 \mathrm{~h}$. The S-phase population of cells was then measured using the BrdU Flow Kit. The flow cytometry 
profiles were acquired using a FACS Calibur (Becton Dickinson). Approximately 10000 cells were analyzed per sample. All flow cytometry data were analyzed using the FlowJo software (Tree Star, Ashland, OR, USA).

\section{Quantitative real-time $P C R$ ( $R T-q P C R$ )}

Total RNA was extracted using the TRIZOL reagent (Invitrogen) and further purified with the PureLink RNA Mini Kit (Invitrogen). A 200-ng sample of total RNA was reverse-transcribed with the Superscript III Reverse Transcriptase (Invitrogen), using $10 \mu \mathrm{M}$ random hexamer primers (Roche) for the Superscript Reverse Transcriptase (Invitrogen), according to the manufacturer's instructions. qPCR amplification was performed with a 7300 real-time PCR system (Applied Biosystems, Foster City, CA, USA) using the Platinum SYBR Green qPCR Supermix-UDG with ROX (Invitrogen), using specific primers $(200 \mathrm{~nm})$ as listed in Supplementary Table S2. In each experiment, the housekeeping genes, $P P I B$ and $Y W H A Z$, were amplified as a reference standard for normalization. The expression of each target gene was normalized to the expression of the housekeeping genes and presented relative to the corresponding siControl sample.

\section{Immunohistochemistry}

RCC tissues and their normal kidney counterparts embedded in paraffin blocks were obtained from Dunedin Hospital with informed consent for research use. Approval for using archival specimens was obtained from the New Zealand Multi-Region Ethics Committee. Immunohistochemical staining was performed as described by He et al. (2010). Sections were stained using a 3,3'-diaminobenzidine chromogen and couterstaining with hematoxylin. The PAX8 antibody (PA 0300; Biopat) was used at 1:2000.

\section{Immunoblotting}

Cells were trypsinized, washed in phosphate-buffered saline(PBS) and lysed on ice for $30 \mathrm{~min}$. The lysis buffer contained $50 \mathrm{~mm}$ Tris- $\mathrm{HCl}(\mathrm{pH} 8.0), 150 \mathrm{~mm} \mathrm{NaCl}, 1 \% \mathrm{NP}-40,0.5 \%$ sodium deoxycholate, $0.1 \%$ sodium dodecyl sulfate (SDS), $1 \times$ Complete Mini Protease Inhibitor Mixture (Roche), $1 \mathrm{~mm}$ sodium orthovanadate and $1 \mathrm{~mm}$ phenylmethylsulfonyl fluoride. Whole-cell lysates were centrifuged $(16100 \mathrm{~g}$ for $20 \mathrm{~min}$ at $4{ }^{\circ} \mathrm{C}$ ) and protein quantification was carried out using the colorimetric BCA Protein Assay Kit (Pierce, Rockford, IL, USA). In all cases, $40 \mu \mathrm{g}$ of the lysates were boiled in the $1 \times$ reducing sample buffer containing $60 \mathrm{~mm}$ Tris- $\mathrm{HCl}(\mathrm{pH} 6.8)$, $60 \mathrm{~mm}$ SDS, $10 \%$ glycerol, $5 \% \beta$-mercaptoethanol and $0.005 \%$ bromophenol blue. The resulting protein samples were then separated by SDS-PAGE and electroblotted onto nitrocellulose membranes. The membranes were blocked with PBS containing $2.5 \%$ non-fat dried milk and probed overnight with primary antibodies. The primary antibodies used have been described earlier. The secondary antibodies used was horseradish peroxidase-conjugated goat anti-mouse antibody or goat anti-rabbit (Sigma, St Louis, MO, USA) antibody. Signals were visualized using the SuperSignal West Pico Chemiluminescent Substrate (Pierce).

\section{MG132 treatment}

$\mathrm{K} 1$ cells were transfected with siRNA and then with DNA constructs as described earlier. At $72 \mathrm{~h}$ after siRNA transfection, the cells were incubated with the proteasome inhibitor MG132 (20 $\mu$; Sigma) for $12 \mathrm{~h}$. The cells were collected for immunoblotting as described above. The total amount of plasmid constructs transfected was $1 \mu \mathrm{g}$ (per well in a six-well plate). To overexpress RB, a mixture containing $500 \mathrm{ng}$ of pCMV-RB and $500 \mathrm{ng}$ of pCR3.1 was used; $1 \mu \mathrm{g}$ of pCR3.1 was used for negative control.

\section{Reporter assay}

K1 cells were reverse-transfected with siRNA (to yield $30 \%$ confluence the following day) and then with DNA constructs as described earlier. For DNA transfection, the cells were transfected with a total amount of $250 \mathrm{ng}$ of DNA (per well in a 24-well plate). The DNA mixture contained $100 \mathrm{ng}$ of pE2F1-Luc or pGL2-basic, $100 \mathrm{ng}$ of pCMV-Pax8 or pCR3.1 and $50 \mathrm{ng}$ pCMV- $\beta$-gal. At $48 \mathrm{~h}$ post DNA transfection, the cells were lysed and luciferase and $\beta$-gal activities were measured using the Luciferase Assay System (Promega) following the manufacturer's instructions. Relative luciferase units were obtained by normalizing luciferase activities to $\beta$-gal.

\section{ChIP and ChIP-qPCR}

A498 cells were grown to $90-95 \%$ confluence in $10-\mathrm{cm}$ plates. Four plates were used for each ChIP reaction. Formaldehyde was added to the culture medium to a final concentration of $1 \%$ and cross-linking was carried out for $10 \mathrm{~min}$ at room temperature. Cross-linking was stopped by adding glycine to a final concentration of $0.125 \mathrm{M}$. After a 5-min incubation period at room temperature, the cells were washed in cold PBS and harvested by scraping cells in $0.75 \mathrm{ml}$ sonication buffer $(50 \mathrm{~mm}$ Tris- $\mathrm{HCl}(\mathrm{pH} 8.0), 10 \mathrm{~mm}$ EDTA, $1 \%$ SDS, $1 \times$ Complete Mini Protease Inhibitor Mixture, $1 \mathrm{~mm}$ sodium orthovanadate and $1 \mathrm{~mm}$ phenylmethylsulfonyl fluoride). The cells were sonicated 10 times for $15 \mathrm{~s}$ at $25 \%$ amplitude to generate fragments of $\sim 200-850 \mathrm{bp}$. Samples were then centrifuged at $12000 \mathrm{~g}$ for $10 \mathrm{~min}$ at $4{ }^{\circ} \mathrm{C}$ and the supernatants (chromatin) were collected. Chromatin was diluted 2.5 times in dilution buffer ( 2 mм EDTA, $100 \mathrm{~mm} \mathrm{NaCl}, 20 \mathrm{~mm}$ Tris- $\mathrm{HCl}$ (pH 8.0) and $0.5 \%$ Triton X-100). Samples were pre-cleared with Dynabeads Protein-G (Invitrogen) for $2 \mathrm{~h}$ at $4{ }^{\circ} \mathrm{C}$. Pre-cleared samples were then incubated for $16 \mathrm{~h}$ with the indicated antibody $(4 \mu \mathrm{g})$ or without an antibody (mock) as negative control. Complexes were then recovered by incubating the samples with $50 \mu \mathrm{l}$ Dynabeads for $4 \mathrm{~h}$ at $4{ }^{\circ} \mathrm{C}$. The immunoprecipitates were then serially washed twice with $1 \mathrm{ml}$ of lowsalt wash buffer ( 2 mM EDTA, 20 mM Tris- $\mathrm{HCl}$ ( $\mathrm{pH} 8.0), 0.1 \%$ SDS, $1 \%$ Triton $\mathrm{X}-100$ and $150 \mathrm{~mm} \mathrm{NaCl}$ ), high-salt wash buffer (20 mm Tris- $\mathrm{HCl}$ (pH 8.0), 2 mm EDTA, 0.1\% SDS, $1 \%$ Triton X-100 and $500 \mathrm{~mm} \mathrm{NaCl}), \mathrm{LiCl}$ wash buffer $(10 \mathrm{~mm}$ Tris- $\mathrm{HCl}$ (pH 8.0), 1 mm EDTA, 1\% NP-40, 1\% deoxycholate, $0.25 \mathrm{M} \mathrm{LiCl})$ and then with $\mathrm{TE}$ buffer $(10 \mathrm{~mm}$ Tris- $\mathrm{HCl}$ (pH 8.0), 1 mм EDTA). Immune complexes were eluted from the beads by boiling in $50 \mu \mathrm{l}$ Chelex-100 (10\% wt/vol), proteinase-K $(20 \mu \mathrm{g})$ digestion and boiling again as described by Dahl and Collas (2008). After the final boiling step, samples were centrifuged at $12000 \mathrm{~g}$ for $2 \mathrm{~min}$ at $4{ }^{\circ} \mathrm{C}$. The eluted ChIP DNA was collected. A $50-\mu 1$ volume of sterile distilled water was added to the mixture, centrifuged and pooled with the first eluted sample. For input DNA, the supernatant from the negative control sample was precipitated with three volumes of $100 \%$ ethanol for $30 \mathrm{~min}$ at $-80^{\circ} \mathrm{C}$. The precipitated DNA was collected by centrifugation at $16100 \mathrm{~g}$ for $10 \mathrm{~min}$ at $4{ }^{\circ} \mathrm{C}$. The DNA pellet was washed in $70 \%$ ethanol, centrifuged and dried, and then dissolved in $450 \mu$ of Chelex-100 overnight at $4{ }^{\circ} \mathrm{C}$, and purified as described above.

Equal amount of DNA (50 ng) was used for each qPCR. Primer information is listed in Supplementary Table S3. An input standard curve dilution series was used for determining primer amplification efficiency, which was used for normalizing the ChIP-DNA signal to the input DNA signal. The fold 
enrichment for promoter occupancy was calculated using $2\left(\Delta \Delta C_{\mathrm{t}}\right)$, where $\Delta \Delta C_{\mathrm{t}}=\left(C_{\mathrm{t}}(\mathrm{IP})-C_{\mathrm{t}}(\right.$ input $\times$ dilution factor $))-\left(C_{\mathrm{t}}(\right.$ mock $)-C_{\mathrm{t}}$ (input $\times$ dilution factor $\left.)\right)$.

\section{Co-immunoprecipitation}

A498 cells were grown to $90-95 \%$ confluence in $10-\mathrm{cm}$ plates Four plates were used for each IP reaction. IP was performed using the protocol from Zhang et al. (2007), with modifications. The cells were washed in cold PBS twice and collected by scraping. The cell suspension was centrifuged at $300 \mathrm{~g}$ for $10 \mathrm{~min}$ at $4{ }^{\circ} \mathrm{C}$. Cells were resuspended in cold PBS containing $10 \mathrm{~nm}$ dimethyl pimelimidate. $2 \mathrm{HCl}$ (DMP) to crosslink the cellular proteins. Crosslinking was performed at $4{ }^{\circ} \mathrm{C}$ for $2 \mathrm{~h}$ and terminated with $50 \mathrm{~mm}$ Tris- $\mathrm{HCl}(\mathrm{pH} 8.0)$ at room temperature for $15 \mathrm{~min}$. The cell suspension was centrifuged as described before and lysed using the immunoblotting lysis buffer. IP was performed as described for ChIP. A sample incubated with an unrelated antibody (anti-CD40) was used as negative control. Immune complexes were recovered using Dynabeads as described above and eluted by boiling the beads in $1 \times$ reducing sample buffer. Immunoblotting was performed as described, with the following modifications. Instead of using a horseradish peroxidase-conjugated secondary antibody, membranes were incubated with the Clean-Blot IP Detection Reagent (Pierce), diluted at 1:200, for $3 \mathrm{~h}$ at room temperature to avoid interference from $\mathrm{IgH}$.

\section{Conflict of interest}

The authors declare no conflict of interest.

\section{References}

Berezutskaya E, Bagchi S. (1997). The human papillomavirus E7 oncoprotein functionally interacts with the S4 subunit of the $26 \mathrm{~S}$ proteasome. J Biol Chem 272: 30135-30140.

Bouchard M, Souabni A, Mandler M, Neubuser A, Busslinger M. (2002). Nephric lineage specification by Pax2 and Pax8. Genes Dev 16: 2958-2970.

Bowen NJ, Logani S, Dickerson EB, Kapa LB, Akhtar M, Benigno $\mathrm{BB}$ et al. (2007). Emerging roles for PAX8 in ovarian cancer and endosalpingeal development. Gynecol Oncol 104: 331-337.

Boyer SN, Wazer DE, Band V. (1996). E7 protein of human papilloma virus-16 induces degradation of retinoblastoma protein through the ubiquitin-proteasome pathway. Cancer Res 56: 4620-4624.

Burkhart DL, Sage J. (2008). Cellular mechanisms of tumour suppression by the retinoblastoma gene. Nat Rev Cancer 8: 671-682.

Buttitta LA, Edgar BA. (2007). Mechanisms controlling cell cycle exit upon terminal differentiation. Curr Opin Cell Biol 19: 697-704.

Chan HM, Krstic-Demonacos M, Smith L, Demonacos C, La Thangue NB. (2001). Acetylation control of the retinoblastoma tumour-suppressor protein. Nat Cell Biol 3: 667-674.

Chellappan SP, Hiebert S, Mudryj M, Horowitz JM, Nevins JR. (1991). The E2F transcription factor is a cellular target for the RB protein. Cell 65: 1053-1061.

Chen YJ, Campbell HG, Wiles AK, Eccles MR, Reddel RR, Braithwaite AW et al. (2008). PAX8 regulates telomerase reverse transcriptase and telomerase RNA component in glioma. Cancer Res 68: 5724-5732.

Dahl E, Koseki H, Balling R. (1997). Pax genes and organogenesis. Bioessays 19: 755-765.

Dahl JA, Collas P. (2008). A rapid micro chromatin immunoprecipitation assay (microChIP). Nat Protoc 3: 1032-1045.

Daniel L, Lechevallier E, Giorgi R, Sichez H, Zattara-Cannoni H, Figarella-Branger D et al. (2001). Pax-2 expression in adult renal tumors. Hum Pathol 32: 282-287.

Dyson N. (1998). The regulation of E2F by pRB-family proteins. Genes Dev 12: 2245-2262.

\section{Acknowledgements}

We thank Dr Kiyoshi Ohtani for providing the pE2F1-Luc construct, Drs Stephen Hsu and Edward Harlow for the pCMV-RB plasmid, Dr Roberto Di Lauro for the pCMV-Pax8 plasmid, Dr Kyle Beggs for reagents, Dr D Wynford-Thomas for K1 cells and Dr Noelyn Hung for the human adult kidney and RCC sections. We also thank $\mathrm{Mr}$ Chris Kenny for blind counting of SA- $\beta$-gal cells, Drs Noelyn Hung and Hitomi Miyata-Watanabe for advice on renal tissue histology, Dr Adele Woolley for advice on immunohistochemical imaging, Dr Philip Kaldis for critical reading of the manuscript and Drs Cathal Mahon and Phil Daniel for technical suggestions.

Grant support: MRE and AWB are supported by funds from the New Zealand Institute for Cancer Research Trust (Otago) and the CMRI (Sydney), respectively. CGL was supported by the Health Research Council, the University of Otago International Fees Scholarship and Postgraduate Publishing Bursary and the Dunedin School of Medicine Finishing Your PhD Scholarship. This work was supported by grants from the Health Research Council of New Zealand and the University of Otago Faculty of Medicine Trust Fund.

Author contributions: MRE, AWB and CGL conceived the study, CGL designed and conducted the experiments and analyzed data together with MRE, and AWB. JEN designed the ChIP-PCR primers, and together with CGL optimized the ChIP-PCRs. CGL and MRE prepared the first draft of the manuscript. All authors contributed to the final manuscript.

Eccles MR, Yun K, Reeve AE, Fidler AE. (1995). Comparative in situ hybridization analysis of PAX2, PAX8, and WT1 gene transcription in human fetal kidney and Wilms' tumors. Am J Pathol 146: 40-45.

Esposito C, Miccadei S, Saiardi A, Civitareale D. (1998). PAX 8 activates the enhancer of the human thyroperoxidase gene. Biochem $J$ 331(Part 1): 37-40

Fabbro D, Pellizzari L, Mercuri F, Tell G, Damante G. (1998). Pax-8 protein levels regulate thyroglobulin gene expression. $J \mathrm{Mol}$ Endocrinol 21: 347-354.

Fernandez PC, Frank SR, Wang L, Schroeder M, Liu S, Greene J et al. (2003). Genomic targets of the human c-Myc protein. Genes Dev 17: $1115-1129$.

Flemington EK, Speck SH, Kaelin Jr WG. (1993). E2F-1-mediated transactivation is inhibited by complex formation with the retinoblastoma susceptibility gene product. Proc Natl Acad Sci USA 90: 6914-6918.

Frolov MV, Dyson NJ. (2004). Molecular mechanisms of E2Fdependent activation and pRB-mediated repression. J Cell Sci 117(Part 11): 2173-2181.

He S, Yoon HS, Suh BJ, Eccles MR.. (2010). PAX3 is extensively expressed in benign and malignant tissues of the melanocytic lineage in humans. $J$ Invest Dermatol 130: 1465-1468.

Hibbs K, Skubitz KM, Pambuccian SE, Casey RC, Burleson KM, Oegema Jr TR et al. (2004). Differential gene expression in ovarian carcinoma: identification of potential biomarkers. Am J Pathol 165: 397-414.

Higashitsuji H, Itoh K, Nagao T, Dawson S, Nonoguchi K, Kido T et al. (2000). Reduced stability of retinoblastoma protein by gankyrin, an oncogenic ankyrin-repeat protein overexpressed in hepatomas. Nat Med 6: 96-99.

Hofmann F, Martelli F, Livingston DM, Wang Z. (1996). The retinoblastoma gene product protects $\mathrm{E} 2 \mathrm{~F}-1$ from degradation by the ubiquitin-proteasome pathway. Genes Dev 10: 2949-2959.

Hooghe B, Hulpiau P, van Roy F, De Bleser P. (2008). ConTra: a promoter alignment analysis tool for identification of transcription 
factor binding sites across species. Nucleic Acids Res 36(Web Server issue): W128-W132.

Hsu SI, Yang CM, Sim KG, Hentschel DM, O'Leary E, Bonventre JV. (2001). TRIP-Br: a novel family of PHD zinc finger- and bromodomain-interacting proteins that regulate the transcriptional activity of E2F-1/DP-1. EMBO J 20: 2273-2285.

Hueber PA, Waters P, Clark P, Eccles M, Goodyer P. (2006). PAX2 inactivation enhances cisplatin-induced apoptosis in renal carcinoma cells. Kidney Int 69: 1139-1145.

Johnson DG, Ohtani K, Nevins JR. (1994). Autoregulatory control of E2F1 expression in response to positive and negative regulators of cell cycle progression. Genes Dev 8: 1514-1525.

Kalejta RF, Shenk T. (2003). Proteasome-dependent, ubiquitinindependent degradation of the $\mathrm{Rb}$ family of tumor suppressors by the human cytomegalovirus pp71 protein. Proc Natl Acad Sci USA 100: 3263-3268.

Kelly K, Cochran BH, Stiles CD, Leder P. (1983). Cell-specific regulation of the c-myc gene by lymphocyte mitogens and plateletderived growth factor. Cell 35(3 Part 2): 603-610.

Knight JS, Sharma N, Robertson ES. (2005). Epstein-Barr virus latent antigen $3 \mathrm{C}$ can mediate the degradation of the retinoblastoma protein through an SCF cellular ubiquitin ligase. Proc Natl Acad Sci USA 102: 18562-18566.

Leung JY, Ehmann GL, Giangrande PH, Nevins JR. (2008). A role for Myc in facilitating transcription activation by E2F1. Oncogene 27: 4172-4179.

Little MH, Bertram JF. (2009). Is there such a thing as a renal stem cell? J Am Soc Nephrol 20: 2112-2117.

Long KB, Srivastava A, Hirsch MS, Hornick JL. (2010). PAX8 expression in well-differentiated pancreatic endocrine tumors: correlation with clinicopathologic features and comparison with gastrointestinal and pulmonary carcinoid tumors. Am J Surg Pathol 34: 723-729.

Macchia PE, Lapi P, Krude H, Pirro MT, Missero C, Chiovato L et al. (1998). PAX8 mutations associated with congenital hypothyroidism caused by thyroid dysgenesis. Nat Genet 19: 83-86.

Manning AL, Longworth MS, Dyson NJ. (2010). Loss of pRB causes centromere dysfunction and chromosomal instability. Genes Dev $\mathbf{2 4}$ : 1364-1376.

Mansouri A, Chowdhury K, Gruss P. (1998). Follicular cells of the thyroid gland require Pax8 gene function. Nat Genet 19: 87-90.

Miccadei S, Provenzano C, Mojzisek M, Natali PG, Civitareale D. (2005). Retinoblastoma protein acts as $\operatorname{Pax} 8$ transcriptional coactivator. Oncogene 24: 6993-7001.

Munro S, Khaire N, Inche A, Carr S, La Thangue NB. (2010). Lysine methylation regulates the $\mathrm{pRb}$ tumour suppressor protein. Oncogene 29: 2357-2367.

Narlis M, Grote D, Gaitan Y, Boualia SK, Bouchard M. (2007). Pax2 and Pax8 regulate branching morphogenesis and nephron differentiation in the developing kidney. J Am Soc Nephrol 18: 1121-1129.

Nitta RT, Jameson SA, Kudlow BA, Conlan LA, Kennedy BK. (2006). Stabilization of the retinoblastoma protein by A-type nuclear lamins is required for INK4A-mediated cell cycle arrest. Mol Cell Biol 26: 5360-5372.

Ohno M, Zannini M, Levy O, Carrasco N, di Lauro R. (1999). The paired-domain transcription factor Pax8 binds to the upstream enhancer of the rat sodium/iodide symporter gene and participates in both thyroid-specific and cyclic-AMP-dependent transcription. Mol Cell Biol 19: 2051-2060.

Peeper DS, Dannenberg JH, Douma S, te Riele H, Bernards R. (2001). Escape from premature senescence is not sufficient for oncogenic transformation by Ras. Nat Cell Biol 3: 198-203.

Pfeffer PL, Gerster T, Lun K, Brand M, Busslinger M. (1998). Characterization of three novel members of the zebrafish Pax2/5/8 family: dependency of Pax5 and Pax8 expression on the Pax2.1 (noi) function. Development 125: 3063-3074.

Plachov D, Chowdhury K, Walther C, Simon D, Guenet JL, Gruss P. (1990). Pax8, a murine paired box gene expressed in the developing excretory system and thyroid gland. Development 110: 643-651.
Poleev A, Wendler F, Fickenscher H, Zannini MS, Yaginuma K, Abbott C et al. (1995). Distinct functional properties of three human paired-boxprotein, PAX8, isoforms generated by alternative splicing in thyroid, kidney and Wilms' tumors. Eur J Biochem 228: 899-911.

Rossi DL, Acebron A, Santisteban P. (1995). Function of the homeo and paired domain proteins TTF-1 and Pax-8 in thyroid cell proliferation. J Biol Chem 270: 23139-23142.

Sage J, Miller AL, Perez-Mancera PA, Wysocki JM, Jacks T. (2003). Acute mutation of retinoblastoma gene function is sufficient for cell cycle re-entry. Nature 424: 223-228.

Sdek P, Ying H, Chang DL, Qiu W, Zheng H, Touitou R et al. (2005). MDM2 promotes proteasome-dependent ubiquitin-independent degradation of retinoblastoma protein. Mol Cell 20: 699-708.

Sellers WR, Novitch BG, Miyake S, Heith A, Otterson GA, Kaye FJ et al. (1998). Stable binding to E2F is not required for the retinoblastoma protein to activate transcription, promote differentiation, and suppress tumor cell growth. Genes Dev 12: 95-106.

Skapek SX, Pan YR, Lee EY. (2006). Regulation of cell lineage specification by the retinoblastoma tumor suppressor. Oncogene $\mathbf{2 5}$ : 5268-5276.

Stoykova A, Gruss P. (1994). Roles of Pax-genes in developing and adult brain as suggested by expression patterns. $J$ Neurosci 14 (3 part 2): $1395-1412$.

Tong GX, Melamed J, Mansukhani M, Memeo L, Hernandez O, Deng FM et al. (2006). PAX2: a reliable marker for nephrogenic adenoma. Mod Pathol 19: 356-363.

Tong GX, Yu WM, Beaubier NT, Weeden EM, Hamele-Bena D, Mansukhani MM et al. (2009). Expression of PAX8 in normal and neoplastic renal tissues: an immunohistochemical study. Mod Pathol 22: $1218-1227$.

Vilain C, Rydlewski C, Duprez L, Heinrichs C, Abramowicz M, Malvaux P et al. (2001). Autosomal dominant transmission of congenital thyroid hypoplasia due to loss-of-function mutation of PAX8. J Clin Endocrinol Metab 86: 234-238.

Weinberg RA. (1995). The retinoblastoma protein and cell cycle control. Cell 81: 323-330.

Wells J, Yan PS, Cechvala M, Huang T, Farnham PJ. (2003). Identification of novel $\mathrm{pRb}$ binding sites using $\mathrm{CpG}$ microarrays suggests that E2F recruits $\mathrm{pRb}$ to specific genomic sites during $\mathrm{S}$ phase. Oncogene 22: 1445-1460.

Wyllie FS, Haughton MF, Rowson JM, Wynford-Thomas D. (1999). Human thyroid cancer cells as a source of isogenic, isophenotypic cell lines with or without functional p53. Br J Cancer 79: $1111-1120$.

Yen A, Coder D, Varvayanis S. (1997). Concentration of RB protein in nucleus vs cytoplasm is stable as phosphorylation of $\mathrm{RB}$ changes during the cell cycle and differentiation. Eur J Cell Biol 72: $159-165$.

Zalmas LP, Zhao X, Graham AL, Fisher R, Reilly C, Coutts AS et al. (2008). DNA-damage response control of E2F7 and E2F8. EMBO Rep 9: 252-259.

Zannini M, Francis-Lang H, Plachov D, Di Lauro R. (1992). Pax-8, a paired domain-containing protein, binds to a sequence overlapping the recognition site of a homeodomain and activates transcription from two thyroid-specific promoters. Mol Cell Biol 12: 4230-4241.

Zhang L, Rayner S, Katoku-Kikyo N, Romanova L, Kikyo N. (2007). Successful co-immunoprecipitation of Oct4 and Nanog using crosslinking. Biochem Biophys Res Commun 361: 611-614.

Zhang P, Zuo H, Nakamura Y, Nakamura M, Wakasa T, Kakudo K. (2006). Immunohistochemical analysis of thyroid-specific transcription factors in thyroid tumors. Pathol Int 56: 240-245.

This work is licensed under the Creative Commons Attribution-NonCommercial-Share Alike 3.0

Unported License. To view a copy of this license, visit http://creativecommons.org/licenses/by-nc-sa/3.0/

Supplementary Information accompanies the paper on the Oncogene website (http://www.nature.com/onc) 